\title{
Uma análise da produção científica em contabilidade gerencial e de custos no Brasil
}

\section{An Analysis of the scientific production in management and costs accounting in Brazil}

\author{
Aline Cristina da Silva ${ }^{1}$, Ângelo Antônio Davis de Oliveira Nunes e Rodrigues ${ }^{2}$ \\ ${ }^{1,2}$ Curso de Ciências Contábeis do Centro Universitário da Fundação Educacional de Barretos (UNIFEB)
}

\begin{abstract}
Resumo
O objetivo da presente pesquisa é ressaltar a evolução da análise científica em contabilidade gerencial e de custos, mostrando os principais temas que foram abordados nos últimos três anos, utilizando o método descritivo e qualitativo para identificar e investigar a análise da produção científica em contabilidade gerencial e em especial a de custos no Brasil. Os resultados da pesquisa mostram que entre os temas abordados nesses três últimos anos a contabilidade de custos foi a temática mais estudada no Brasil, mostrando que as técnicas de custos são uma ferramenta indispensável para o crescimento e desenvolvimento das empresas.
\end{abstract}

Palavras-chave: Contabilidade Gerencial, Contabilidade de Custos, Pesquisa.

\begin{abstract}
The objective of the present research is to highlight the evolution of the scientific analysis in management and cost accounting, showing the main themes that were addressed in the last three years. For this, it was used the descriptive and qualitative method to identify and investigate the analysis of the scientific production in management accounting and especially of costs in Brazil. The results showed that among the themes, the cost accounting was the most discussed topic in Brazil, showing that is an indispensable tool for the growth and development of companies.
\end{abstract}

Keywords: Managerial Accounting; Cost Accounting; Research.

Autor correspondente: Ângelo Antônio Davis de Oliveira Nunes e Rodrigues E-mail: angelo.rodrigues@ unifeb.edu.br

Recebido para publicação em: 10/03/2019

Aceito para publicação em: 07/10/2019

https://doi.org/10.4322/1980-0029.102020 


\section{Introdução}

No século XVIII até a Revolução Industrial predominava a Contabilidade Financeira, que foi estruturada na Era Mercantilista, para atender as empresas comerciais (Martins, 2010).

Assim, o levantamento do balanço era feito por meio do controle dos estoques físicos, pois as medidas tomadas eram muito simples, por isso o contador apurava o valor pago por item estocado e colocava valores nas mercadorias (Martins, 2010).

Segundo o mesmo autor, com o crescimento das empresas os gestores acabaram se distanciando dos ativos e das pessoas administradas, portanto a contabilidade de custos passou a ser considerada como uma eficaz forma de contribuição para o desempenho de uma nova missão, sendo ela a gerencial.

Nas últimas décadas, a contabilidade de custos passou de uma simples auxiliar de avaliação de estoques e lucros para uma importante arma de controle e decisão gerenciais (Martins, 2010).

A contabilidade de custos com o passar do tempo se tornou uma ferramenta competente para os empresários permanecerem ativos no mercado, pois ela ajuda a promover o crescimento da empresa, levantando dados importantes e precisos para a tomada de decisões (Sousa et al., 2015).

Nesse sentido, houve um grande crescimento na competitividade nos mercados, sejam eles industriais, comerciais ou de serviços, por isso os custos são de extrema importância na tomada de decisões em uma empresa (Martins, 2010).

Portanto, o objetivo da contabilidade de custos é classificar o estoque e o custo para comprovar o resultado da demonstração contábil constituindo informes para planejar e tomar decisões corretas para o crescimento da empresa (Sousa et al., 2015).

O conhecimento dos custos é essencial para a eficácia na tomada de decisões dos negócios, para se destacar neste meio competitivo, é preciso se destacar em meio aos concorrentes, tendo conhecimento, informações precisas sobre custos diretos e indiretos e conhecimentos dos parâmetros de rateio usado (Elias et al., 2009).

Assim, o objetivo desta pesquisa é apontar o estado da arte do conhecimento acerca da contabilidade gerencial, em especial a de custos no Brasil.
Diante dos apontamentos sobre a contabilidade: Quais são os principais temas de contabilidade gerencial e de custos utilizadas nas pesquisas no Brasil?

Nesse contexto, a contribuição da pesquisa é apontar o desenvolvimento científico acerca do tema estudado, apontando os principais temas abordados nos últimos três anos no país. Para alcançar o objetivo da pesquisa, a introdução apresentou o tema; a teoria abordará um estudo de custos no Brasil, seguida pela metodologia, resultados e conclusão.

\section{História da contabilidade dos custos}

O início das escrituras contábeis é do final da Era da Pedra Polida, onde o homem marcava seus desenhos e gravuras. O aprimoramento e o desenvolvimento da contabilidade foram em decorrência da precisão formada pela chegada do capitalismo, nos séculos XII e XIII. Em que o serviço escravizado passou a ser remunerado (Portal da Contabilidade, 2017).

O crescimento dos mecanismos de levantamento dos custos foi influenciado na precisão das organizações da Era Mercantilista. O levantamento dos rendimentos era feito pelo meio de controle de estoques (Motta, 2000).

A evolução do homem e da sociedade tornou necessária a mudança para se conseguir ter controle da vida e do patrimônio, fato que fez surgir a obrigação do monitoramento. No século XIII ocorreu a Revolução Industrial, em que o objetivo da instigação era determinar o valor da mercadoria fabricada, estimativa dos estoques das fábricas, diante da grande precisão foi que surgiu a contabilidade de custos (Sousa et al., 2015).

O meio organizacional está em frequente transformação para as companhias proporcionarem modificações para preservar seu negócio e tomar decisões rápidas com peculiaridade. As transformações exigidas às companhias as levam a elaborar seus meios de conhecimentos procurando padrões que se encaixem às estruturas melhorando sua gestão e o reconhecimento de seus pontos negativos (Rosa, 2010).

$\mathrm{Na}$ atualidade a concorrência é acirrada, o que leva as organizações a apresentarem um melhor controle em sua produtividade no qual os cálculos resultem em lucro ou prejuízo. Com as inovações tecnológicas surge a possibilidade de economia de recursos e aumento na produção, com 
isso o contador precisa de meios gerenciais para identificar os custos relacionados à produtividade (Crepaldi et al., 2017).

Segundo os mesmos autores, a contabilidade de custos determina o domínio de custeios por meios gerenciais para procurar um entendimento concreto do processo de produção e da quantidade que está sendo contratada para fabricar cada produto, facilitando o gestor entender o valor que será gasto para produzir cada produto.

Com a vinda das regras internacionais de contabilidade, o Brasil e demais países visam promover homogeneidade nas demonstrações contábeis provocando diminuição de custos de empresas, propiciando o mercado e constituindo eficácia para as organizações (Agostini \& Carvalho, 2017).

Para Fernandes (2012), a aplicação de um método de custeio é simples, mas deve ocorrer com exatidão no momento em que a classificação dos custos for feita. A categoria dos custos pode ocorrer conforme a fácil identificação dos produtos, e recebe uma especificação em relação à quantidade produzida em certo produto.

São várias as formas de avaliar os custos. Os métodos de custeio atuais são: custeio por absorção, custeio direto ou variável e custeio baseado em atividades, no entanto o método aprovado pela legislação societária é o custeio por absorção, por respeitar o regime de competência e os Princípios Fundamentais da Contabilidade (Albanez et al., 2008).

Nesse sentido, cada método de custeio contém particularidades, ganhos e perdas. A estrutura de informe contábil é capacitada para produzir informações diversas, de acordo com a forma de decisão a ser tomada, concernindo aos gestores identificar as diversas ferramentas disponíveis pela contabilidade e torná-las pertinentes no processo decisório.

As empresas avaliam seus custos porque estão apreensivas com a competição por preço, que sofre impacto direto dos custos e da aplicação de algum método de custeio. A medida precisa de custos é de ampla relevância para analisar a rentabilidade dos produtos, já que não adianta prever valores sem ser realizada confrontação com valores reais incorridos, o que proporciona identificar deslizes e sobrepor medidas corretas de forma oportuna (Albanez et al., 2008).
O custeio por absorção é o método decorrente da utilização dos Princípios de Contabilidade Geralmente Aceitos. Constitui-se na adequação de todos os custos de produção; todas as despesas relacionadas ao esforço de produção são disseminadas para produtos ou serviços realizados. O custeio por absorção no Brasil está contemplado no Pronunciamento Técnico CPC 16, do Comitê de Pronunciamentos Contábeis (CPC), que cuida dos valores de estoques (Martins, 2010).

Para Martins (2010), o custeio baseado em atividades, chamado de Activity-Basead Costing (ABC), é o método de custeio que busca diminuir as deficiências ocasionadas pelo rateio aleatório dos custos indiretos. Nesse método, os custos fixos não se modificam quando a quantidade se modifica (Maher, 2001).

Os custos variáveis se modificam na proporção direta da modificação na quantidade, no meio de uma pausa importante de atividade (Maher, 2001).

Pelos Princípios Contábeis, no Brasil o custeio variável não é permitido nem regularizado para finalidades de auditoria e do fisco; a razão é que esse método de custeio agride os princípios de regime de competência e a confrontação que definem o dever de confiscar as receitas e deduzir os custos. $\mathrm{O}$ fato de esse método não ser aceito não impede que ele seja utilizado de forma gerencial interna, e que depois sejam feitos os devidos ajustes e apropriações (Crepaldi et al., 2017).

Segundo Martins (2010), os custos fixos e as variáveis são os mais importantes, pois fazem a ligação do valor total com a quantidade de movimentação em uma unidade de tempo.

Os custos diretos são aqueles que podem ser adequados em direção aos produtos produzidos em ocasiões que seus recursos e quantidades em ligação aos produtos são de simples reconhecimento, não é necessário fazer o rateio para ser feito o reconhecimento dos custos em relação aos produtos (Almeida \& Camargo, 2009).

Os custos indiretos consistem em cálculos, rateios (divisões) ou estimativas para serem pertinentes em diversos produtos como critério usado para estimativas de suporte ao método de rateio (Almeida \& Camargo, 2009).

O rateio de custos caracteriza classificação de um custo indireto a um objetivo de custo, com um correto suporte. O objetivo do custo por seu lado caracteriza algum fim no qual um custo é atribuído (Maher, 2001). 


\subsection{Estudos de custos no Brasil}

O estudo de Elias et al. (2009) teve como objetivo identificar os melhores critérios de apropriação dos custos indiretos de produção, utilizando métodos estatísticos de correlação e regressão, onde se conclui que não pode ser identificado um critério único de rateio.

Souza et al. (2015) estudaram a importância da contabilidade de custos por meio do custeio de absorção dentro das empresas, foi realizado um estudo de caso, onde se comprova a importância da contabilidade de custos para o controle de gastos e despesas das empresas.

O trabalho realizado por Motta (2000) teve como objetivo analisar e identificar os fatores pessoais e impessoais para adoção de um método de custeio específico para pequenas empresas, utilizando uma metodologia descritiva e exploratória em quatro empresas, identificou-se que o administrador é a peça fundamental para a adoção dos métodos de custeio, através do nível de informação gerencial.

O estudo realizado por Beuren (1993) analisou as origens da contabilidade de custos focada em sua evolução no tempo. Com método de pesquisa descritivo, a contabilidade de custos teve seus primeiros sinais em empresas de comércio e financeiras, assim, com os avanços das últimas décadas, ficou provado o surgimento do custeio variável, que passou a ser utilizado na contabilidade de custo.

O estudo realizado por Carvalho et al. (2008) analisou a implantação da contabilidade analítica ou de custos na administração pública, através de um sistema obrigatório sujeito a normas. Com um estudo empírico, feito em diversas empresas do setor público, a contabilidade analítica ou de custos assume papel importante na organização, auxiliando no processo de tomada de decisão, por meio de análises e controle de custos.

\section{Metodologia}

A classificação metodológica desta pesquisa está baseada em Beuren (1993), que observa o objetivo, o problema e o procedimento.

O objetivo desta pesquisa é descritivo, pois se caracteriza como um estudo entre a pesquisa exploratória e a explicativa, no qual identifica e relata uma análise da produção científica em contabilidade de custos no Brasil.

O problema de pesquisa é qualitativo porque visa destacar uma análise mais profunda sobre o tema estudado, possibilitando investigar sobre a contabilidade de custos no Brasil.

O procedimento é uma análise documental, pois organiza dados que se encontram dispersos, verificando uma nova valia como fonte de consulta.

Assim, para alcançar o objetivo de pesquisa foram verificados os artigos da área de contabilidade gerencial e de custos publicados nos anais do Congresso Universidade de São Paulo de Controladoria e Contabilidade entre o período de 2015 a 2017.

A limitação desta pesquisa é a dificuldade em encontrar trabalhos relacionados a esse tema, dificultando reunir informações suficientes para a elaboração do mesmo, sendo necessário retirar os trabalhos em inglês da amostra.

O objetivo desta pesquisa foi destacar quais os principais temas de contabilidade gerencial e custos estão sendo mais pesquisados no Brasil.

Os dados foram coletados sobre o Congresso USP de Controladoria e Contabilidade, sendo analisados os anos de 2015, 2016 e 2017, no período do mês de outubro de 2017.

A pesquisa encontrou 67 artigos relacionados à contabilidade gerencial, que abordavam 18 diferentes temáticas, sendo a de contabilidade de custos a principal, com 14 artigos.

O Quadro 1 mostra que as três áreas mais pesquisadas foram: contabilidade de custos, contabilidade e controle gerencial e sistemas de controle gerencial. E houve várias áreas menos pesquisadas, entre elas estão: avaliação de desempenho, BSC e orçamento, e do total de 67 artigos, foram abordados 18 diferentes temas.

O Quadro 2 mostra os objetivos pesquisados nos três principais temas e dentre eles se destacam os seguintes objetivos: verificar e analisar os custos dentro das empresas, entender como decisões são tomadas pelos gestores dentro das práticas da contabilidade e controle gerencial dentro das empresas e verificar as dimensões do sistema de controle gerencial dentro das organizações.

Nesse sentido, a contabilidade de custos envolve a mensuração dos custos e a prática de gestão das empresas, analisando o comportamento dos custos e quais os principais fatores que impedem o crescimento da empresa. Auxiliando também o meio organizacional na tomada de decisões para que desempenhem um bom crescimento e ao mesmo tempo preservem suas empresas. 
Quadro 1 - Temas abordados

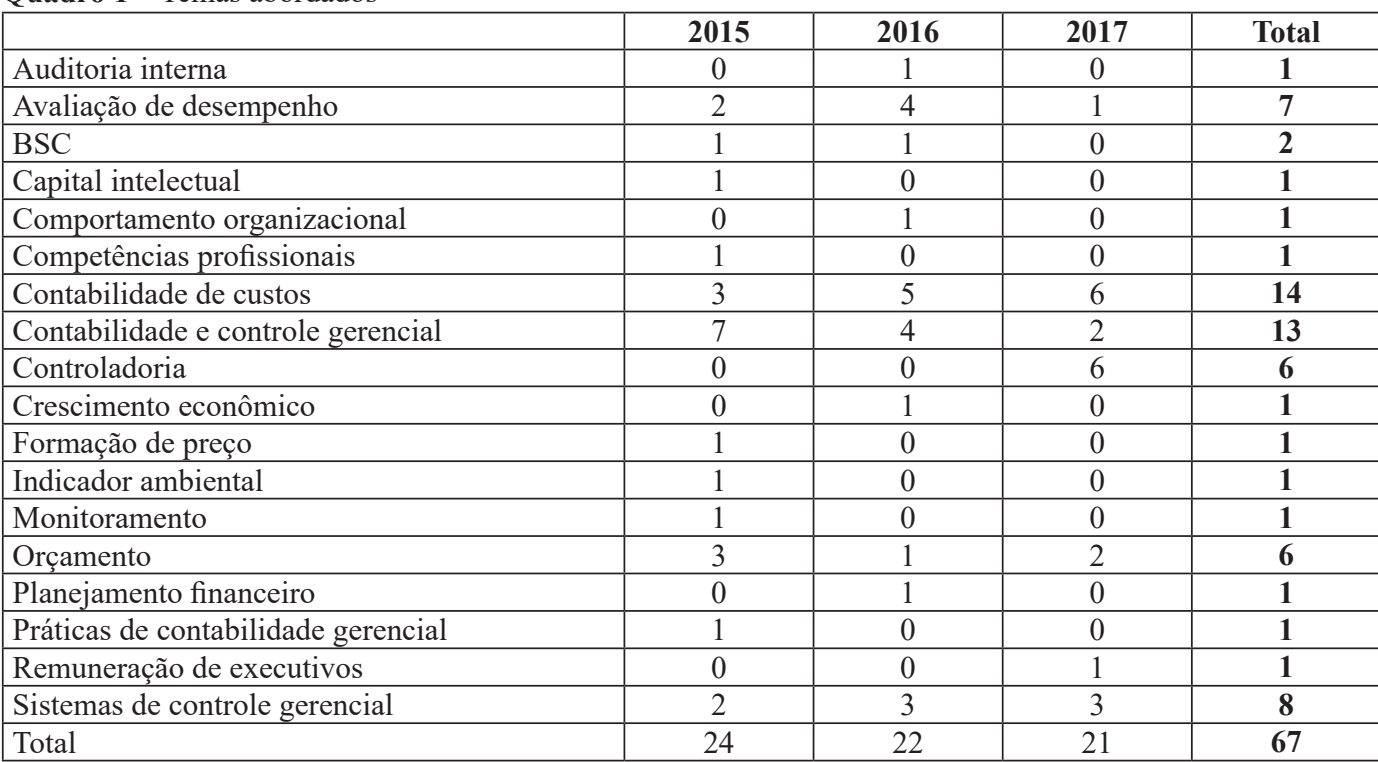

Fonte: Fonte: elaborado pelos autores com base nos anais 2015 a 2017 do Congresso USP de Controladoria e Contabilidade.

Quadro 2-Objetivos

\begin{tabular}{|c|c|}
\hline $\begin{array}{l}\text { Contabilidade de } \\
\text { custos }\end{array}$ & $\begin{array}{l}\text { Analisar a relação custo benefício/custo de implantação do custeio ABC; Verificar os custos } \\
\text { das empresas sob a ótica do sticky costs; Analisar os conceitos da Teoria Ator-Rede (TAR) } \\
\text { ao arcabouço da Gestão Estratégica de Custis (GEC); Investigar o nível de associações } \\
\text { colaborativas para realizar gestão de custos entre empresas brasileiras; Analisar o } \\
\text { comportamento dos custos de empresas dos países que compõem o PIIGS; Analisar quais } \\
\text { os principais fatores que impedem o aumento da produtividade nas empresas; Verificar a } \\
\text { ocorrência e mensuração dos custos da qualidade em empresas; Identificar as práticas de } \\
\text { gestão de custos alinhadas ao posicionamento estratégico das empresas; Propor um modelo } \\
\text { TCO para compra e venda de veículos de transportes rodoviário de cargas; Analisar as } \\
\text { práticas de gestão de custos logísticos tradicionais e da Green Logistic; Verificar os custos } \\
\text { em relação às receitas de vendas nas empresas listadas na BM\&FBovespa; Documentar } \\
\text { a área de custos nos } 20 \text { Accouting Journals presentes na base ISI Web of Science da } \\
\text { Thompson Reuters Scientific; Verificar o comportamento dos custos em períodos de } \\
\text { prosperidade e crise econômica em empresas e países que compõem o PIIGS; Verificar } \\
\text { se a subjetividade na aplicação do valor justo de nível } 3 \text { e os vieses cognitivos afetam o } \\
\text { processo de tomada de decisão de venda por parte dos gestores. }\end{array}$ \\
\hline $\begin{array}{l}\text { Contabilidade de } \\
\text { controle gerencial }\end{array}$ & $\begin{array}{l}\text { Verificar a percepção dos especialistas do Brasil sobre os significados e as diferenciações; } \\
\text { Analisar sobre a abordagem institucional, as implicações da implantação de um } \\
\text { Centro de Serviços Compartilhados (CSC); Entender como decisões são tomadas } \\
\text { do ponto de vista cognitivo; Investigar as necessidades de informações dos gestores } \\
\text { para controlar as perdas de água numa companhia de saneamento; Verificar quais são } \\
\text { as práticas de controle gerencial; Avaliar a relação entre as variáveis contingenciais, } \\
\text { de profissionalização e de aprendizagem organizacional; Realizar uma aplicação } \\
\text { da ferramenta Performance Measurement Qustionnaire (PMQ) no departamento } \\
\text { de controladoria; Analisar as abordagens e metodologias utilizadas em pesquisas } \\
\text { internacionais, que utilizaram a Teoria Institucional; Avaliar os aspectos da produção } \\
\text { científica na perspectiva da contabilidade gerencial e nos periódicos internacionais; } \\
\text { Verificar se existem diferenças quanto ao uso de proxies de controle gerencial em relação } \\
\text { ao gênero do empreendedor-gestor; Relacionar o estágio de ciclo de vida organizacional } \\
\text { com o uso de artefatos de contabilidade gerencial tradicionais e modernos; Tipificar } \\
\text { as perspectivas para o desenvolvimento de novas pesquisas relacionadas à literatura } \\
\text { sobre a incerteza ambiental percebida na contabilidade gerencial. }\end{array}$ \\
\hline
\end{tabular}

Fonte: Fonte: elaborado pelos autores com base nos anais 2015 a 2017 do Congresso USP de Controladoria e Contabilidade. 
Quadro 2 - Continuação...

\begin{tabular}{|c|l|}
\hline \multirow{3}{*}{$\begin{array}{c}\text { Sistemas de controle } \\
\text { gerencial }\end{array}$} & $\begin{array}{l}\text { Verificar quais dimensões do sistema de controle gerencial (SCG) aumentam a percepção } \\
\text { de justiça organizacional e reduzem comportamentos antiéticos; Investigar a relação entre } \\
\text { sistemas de controle gerencial e contratos psicológicos; Examinar a confiança no sistema } \\
\text { de controle gerencial e sua relação com os objetivos organizacionais; Investigar como } \\
\text { ocorre o processo de mudança planejada no sistema de controle gerencial; Examinar } \\
\text { como a relação entre estratégia ambiental e performance gerencial é medida pelo } \\
\text { pacote do SCG; Propor um mapa conceitual das temáticas de controle gerencial (CG) } \\
\text { e SCG; Verificar a influência das ações ambientais na formação de redes mediada pelo } \\
\text { SCG; Verificar os reflexos da aplicação de recursos por provedores de funding no uso } \\
\text { do sistema de controle gerencial medido pelo seu desempenho em empresas startups. }\end{array}$ \\
\hline
\end{tabular}

Fonte: Fonte: elaborado pelos autores com base nos anais 2015 a 2017 do Congresso USP de Controladoria e Contabilidade.

\section{Conclusão}

O objetivo deste trabalho foi evidenciar quais os temas dentro da contabilidade de custos estão sendo mais pesquisados no Brasil. A contabilidade de custos tem papel muito importante no setor gerencial de uma empresa, no qual gera informações próximas à realidade que servirão para auxiliar nas tomadas de decisões.

Assim, a contabilidade de custos diz ao empresário/contador se esse produto poderá lhe trazer lucros ou prejuízos, onde será realizada a tomada de decisão e se é viável ou não continuar a produção desejada.

O estudo foi feito por meio de pesquisa de artigos nos anais do Congresso USP de Controladoria e Contabilidade pelo tema Contabilidade Gerencial. A pesquisa foi realizada nos anos de 2015 a 2017, foram encontrados 67 artigos, com 18 temáticas diferentes, tendo três principais temas abordados: contabilidade de custos, contabilidade e controle gerencial e sistemas de controle gerencial.

Com base nessas informações, a contabilidade de custos mostra-se ligada à contabilidade gerencial, pois as duas visam contribuir para o planejamento e controle de custos/despesas, identificando vantagens e desvantagens no mercado competitivo, e avaliar o desempenho de seus gestores.

\section{Referências}

Agostini, C., \& Carvalho, J. T. A. (2017). A evolução da contabilidade: seus avanços no Brasil e a harmonização com as normas internacionais. Recuperado em 24 de julho de 2017, de http://www.iptan.edu.br/publicacoes/ anuario_producao_cientifica/arquivos/revista1/ artigos/Artigo_Carla_Joziane.pdf

Albanez, T., Bonizio, R. C., \& Ribeiro, E. M. S. (2008). Uma análise da estrutura de custos do setor sucroalcooleiro brasileiro. Revista Custos e Agronegócio, 4(1), 79-102.

Almeida, A., \& Camargo, J. (2009). Gestão e contabilidade de custos (Trabalho de conclusão de curso). Faculdades Integradas de Boituva, Boituva.

Beuren, I. M. (1993). Evolução histórica da contabilidade de custos. Revista Contabilidade Vista \& Revista, 5(1), 61-66.

Carvalho, J., Costa, T. C., \& Macedo, N. (2008). A contabilidade analítica ou de custos no setor público administrativo. Revista TOC, 30-41.

Crepaldi, P. G., Avila, R. N. P., \& Oliveira, A. B. (2017). A influência na contabilidade de custos na tomada de decisões. Recuperado em 24 de julho de 2017, de https://www.inesul.edu.br

Elias, Z. S., Alberton, L., Vicente, E. F. R., Rebello, M., \& Bonifácio, R. R. C. (2009). Rateio dos custos indiretos: aplicação da análise de correlação e de regressão. Revista de Contabilidade do Mestrado em Ciências Contábeis da UFRJ, 14(2), 50-66.

Fernandes, E. M. (2012). Análise de custo na agroindústria: um estudo de caso aplicado em uma empresa do ramo avícola. Recuperado em 28 de maio de 2017, de http://repositorio.unesc. net/handle/1/1298

Maher, M. (2001). Contabilidade de custos. São Paulo: Atlas.

Martins, E. (2010). Contabilidade de custos (10. ed.). São Paulo: Atlas.

Motta, F. G. (2000). Fatores condicionantes na adoção de métodos de custeio em pequenas empresas: estudo multicasos em empresas do setor metal-mecâncio de São Carlos-SP (Dissertação de 
mestrado). Escola de Engenharia de São Carlos, Universidade de São Paulo, São Carlos.

Portal da Contabilidade. (2017). História da contabilidade. Recuperado em 12 de junho de 2017, de http://www.sintec-imp.com.br

Rosa, F. F. (2010). A contabilidade de custos e sua relevância para a gestão (Monografia).
Universidade Federal do Rio Grande do Sul, Porto Alegre.

Sousa, E. J., Duraes, G. R., \& Rodrigues, P. N. (2015). A importância da contabilidade de custos na empresa KM indústria de colchões LTDA. Goiânia: Faculdade FAN Padrão. Recuperado em 28 de maio de 2017, de http://faculdadefanpadrao. com.br/ 